\title{
Administration of Testosterone Attenuates Neuronal Loss Following Axotomy in the Brain-Stem Motor Nuclei of Female Rats
}

\author{
Wan-hua Amy Yu \\ Department of Cell Biology and Anatomical Sciences, City University of New York Medical School, New York, New York \\ 10031
}

This study was undertaken to elucidate whether (1) administration of testosterone to female rats attenuates axotomyinduced neuronal loss; (2) the efficacy of testosterone treatment is related to the age of animals, the dosage given, and the time and duration of the treatment; (3) neurons which project or terminate aberrantly can survive; and (4) the trophic actions of testosterone on neuronal survival and axonal outgrowth are operated under the same mechanisms.

The hypoglossal and facial nerves were transected unilaterally at 3 and 6 weeks of age. In order to establish the dose-response curve, testosterone propionate (TP) at doses of $0.5,1.0,2.0$, or $5.0 \mathrm{mg}$ was injected subcutaneously twice weekly during the first 4 postaxotomy weeks, and once weekly thereafter for an additional 6 weeks. Neuronal numbers in the hypoglossal and facial motor nuclei were counted 10-12 weeks after axotomy in serial paraffin sections stained with cresyl violet. To determine the time course of TP effect, neuronal numbers were counted at 1, 4, 12, and 20 weeks after axotomy. In addition, neuronal loss 12 weeks after axotomy in rats treated with TP for the first 3 postaxotomy weeks only was compared with that in rats withheld TP treatment until the 5th postaxotomy week. To determine axonal projections and terminations of the surviving neurons, HRP retrograde tracing technique was used.

Results indicated that TP treatment significantly attenuated neuronal loss in prepubertal and young adult female rats in a dose- and time-dependent manner. Only doses which elevated serum testosterone to levels comparable to or surpassing normal male levels were effective. Neuronal loss that commenced about a month after axotomy was prevented by TP treatment, but the loss that occurred earlier was unaffected by the treatment. The immediate and brief TP treatment, shown previously capable of accelerating axonal outgrowth, was not sufficient to reduce neuronal loss, whereas the abeyance of hormonal treatments for the first 4 postaxotomy weeks did not diminish its efficacy. Surviving hypoglossal neurons consisted of those projecting normally

\footnotetext{
Received Dec. 27, 1988; revised Apr. 21, 1989; accepted May 5, 1989.

This research was supported by grants 666280 and 667142 from the PSC-CUNY Research Award Program of the City University of New York. The author thanks Aida Lee, Gregory Rudomen, and Mary Wong for cutting paraffin blocks, and Barbara Cooper for typing the manuscript. The author also thanks Dr. Lewis C. Krey for radioimmunoassay of testosterone.

Correspondence should be addressed to Wan-hua Amy Yu, Ph.D., Department of Cell Biology and Anatomical Sciences, City University of New York Medical School, Convent Avenue at 138th Street, New York, NY 10031.

Copyright $(\mathcal{C} 1989$ Society for Neuroscience $0270-6474 / 89 / 113908-07 \$ 02.00 / 0$
}

as well as aberrantly into muscles of the tongue, and those terminating near the transection site.

In conclusion, administration of testosterone attenuates axotomy-induced neuronal loss in female rats. The 2 identified trophic actions of testosterone of accelerating axonal regeneration and promoting neuronal survival occur at different time points, possibly operating under different mechanisms. The time course of its effect on neuronal survival suggests the involvement of target interactions.

It is known that sexually dimorphic motoneurons innervating perineal muscles in the rat lumbar spinal cord contain androgen receptors (Breedlove and Arnold, 1980). These neurons were found to be dependent on androgens to reduce normal neuronal death during development (Nordeen et al., 1985) and to maintain the male characteristic somal size and dendritic length in adults (Kurz et al., 1986). Ncurons in some cranial nerve motor nuclei of adult rodents and primates have also been shown to contain receptors for male sex hormones since they concentrate radiolabeled androgens into their cell nuclei in vivo (Sar and Stumpf, 1977; Sheridan and Weaker, 1981, 1982; Commins and Yahr, 1985). Studies by in vitro binding assays (Yu and McGinnis, 1986) have demonstrated that motor nuclei of the hypoglossal and facial nerves and tongue muscles in adult rats possess a receptor system with properties similar to androgen receptors in the limbic forebrain (McGinnis et al., 1983) and limb muscles (Krieg, 1976; Snochowski et al., 1980). The physiological significance of the presence of androgen receptors in regions of the neural axis outside the realm of reproduction remains to be determined.

In order to assess the responsiveness of motoneurons of cranial nerves to androgenic stimulation, we studied the effects of androgens on motoneurons of the hypoglossal and facial nerves undergoing repair after axonal injury. The available evidence accumulated in our laboratory suggests that the rate of axonal regeneration and survival of motoneurons following axotomy are positively correlated with the levels of androgens in circulation. We reported that the speed of regeneration of the hypoglossal nerve in young adult rats was faster in males than in females or male castrates (Yu, 1982a). Administration of testosterone to young adult rats of both sexes accelerated regeneration of the hypoglossal nerve (Yu and Srinivasan, 1981; Yu, 1982b). Neuronal loss in the hypoglossal and facial motor nuclei induced by nerve transection was significantly less in male than in female or male castrated rats (Yu, 1988). These results suggest that androgen-receptor-containing motoneurons of cranial nerves are responsive to androgens and that androgens exert trophic influences on motoneurons which are not sexually dimorphic. 
Although evidence ascribing neurotrophic attributes to androgens is increasing, the mechanism(s) and site(s) of action of sex steroids on motoneurons are still poorly understood. The present study was undertaken to address the following questions: whether (1) axotomy-induced neuronal loss in female rats can be attenuated by exogenous testosterone; (2) the efficacy of testosterone treatment is related to the age of animals, the dosage given, and the time and duration of the treatment; (3) motoneurons which project or terminate aberrantly can survive; and (4) trophic functions of testosterone on axonal outgrowth and neuronal survival are operated under the same mechanisms.

\section{Materials and Methods}

Animals and surgery. Female Sprague-Dawley rats 3 and 6 weeks of age and weighing 50-60 and 160-180 gm, respectively, were used. Rats were anesthetized with chloral hydrate $(35 \mathrm{mg} / 100 \mathrm{gm}$ body weight) and subjected to either double or single nerve transection. For double lesion, the right hypoglossal nerve was exposed in the neck region and transected proximal to its bifurcation at the level of the belly of the digastric muscle. The left facial nerve was exposed behind the ear and transected distal to its exit from the stylomastoid foramen. For single lesion, only the right hypoglossal nerve was transected. Nerve stumps were apposed as closely as possible without suturing. The axotomized rats were used for the following studies.

Dose-response study. A total of 44 rats double-lesioned at either 3 or 6 weeks of age was used. Of these rats, 34 were assigned to the hormonal treatment group and received subcutaneous injection of testosterone propionate (TP) at doses of $0.5,1.0,2.0$, or $5.0 \mathrm{mg}$ dissolved in $0.1 \mathrm{ml}$ sesame oil twice weekly for the first 4 post axotomy weeks and once weekly thereafter for an additional 6 weeks. The remaining 10 rats were injected with oil vehicle and used as controls. The first injection of TP or oil vehicle was given immediately after axotomy.

Ten weeks (for those rats axotomized at 3 weeks of age) and 12 weeks (for those rats axotomized at 6 weeks of age) after axotomy, rats from both groups were perfused intracardially with $1 \%$ paraformaldehyde-

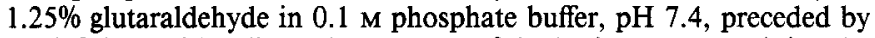
a brief rinse with saline. The segment of the brain stem containing the hypoglossal and facial motor nuclei was dissected out and processed for Paraplast embedment. Serial sections were cut transversely and stained with cresyl violet. Neuronal numbers in the hypoglossal and facial motor nuclei were counted by the procedure described elsewhere (Yu, 1988). The value on the axotomized side was expressed as a percentage of that of the contralateral, intact side. The percent loss in neuronal number on the axotomized side was obtained by subtracting the percent value from 100 .

Radioimmunoassay of plasma testosterone. Blood samples were collected from rats axotomized at 3 weeks of age and treated with different doses of TP. These rats were killed 10 weeks after axotomy. Blood was withdrawn within $16-20 \mathrm{hr}$ of the final TP or oil vehicle injection by cardiac puncture prior to perfusion with the fixative. For comparison purposes, blood samples were also obtained in a similar manner from 8 male rats which were double-lesioned at 3 weeks of age but received no injection, and killed 10 weeks after axotomy. The plasma was separated by centrifugation and stored at $-20^{\circ} \mathrm{C}$ until assay. Plasma testosterone levels were measured by radioimmunoassay using GDN \#250 antiserum generated against a testosterone-11-BSA conjugate and ${ }^{3} \mathrm{H}$ testosterone as tracer as described by Lieberburg et al. (1979).

Time-course study. A total of 23 rats which were double-lesioned at 6 weeks of age was used. Of these rats, 11 were injected with $5 \mathrm{mg}$ TP in $0.1 \mathrm{ml}$ sesame oil by the same schedule described above. The remaining 12 rats were injected with oil vehicle and served as controls. Rats from both groups were killed 1, 4, 12, and 20 weeks after axotomy, and neuronal numbers in the hypoglossal and facial motor nuclei were counted.

Efficacy of immediate versus delayed TP treatment. One group of 6 rats which were double-lesioned at 6 weeks of age was given $5 \mathrm{mg}$ TP injection twice weekly for the first 3 weeks only following axotomy. In another group of 10 rats double-lesioned at 6 weeks of age, the initiation of $5 \mathrm{mg}$ TP treatment was delayed until the 5 th week after axotomy, and TP was given henceforth once weekly for 6 weeks. All rats were killed 12 weeks after axotomy for neuronal cell count.

Tracing of axonal projections and terminations of surviving neurons.
Table 1. Dose-response study on the effect of testosterone treatment on neuronal loss 10-12 weeks after axotomy

\begin{tabular}{|c|c|c|c|}
\hline \multirow[b]{2}{*}{ Group } & \multirow[b]{2}{*}{$n$} & \multicolumn{2}{|c|}{$\%$ Neuronal loss } \\
\hline & & $\begin{array}{l}\text { Hypoglossal } \\
\text { nucleus }\end{array}$ & $\begin{array}{l}\text { Facial } \\
\text { nucleus }\end{array}$ \\
\hline \multicolumn{4}{|c|}{ Axotomy at 3 weeks of age } \\
\hline Controls & 8 & $22.4 \pm 1.5$ & $26.8 \pm 1.7$ \\
\hline $0.5 \mathrm{mg} \mathrm{TP}$ & 7 & $22.6 \pm 1.8$ & $24.6 \pm 1.9$ \\
\hline $1.0 \mathrm{mg} \mathrm{TP}$ & 5 & $13.0 \pm 1.6^{a}$ & $12.0 \pm 2.0^{a}$ \\
\hline $2.0 \mathrm{mg} \mathrm{TP}$ & 5 & $12.0 \pm 1.6^{a}$ & $11.8 \pm 1.3^{a}$ \\
\hline \multicolumn{4}{|c|}{ Axotomy at 6 weeks of age } \\
\hline Controls & 4 & $24.7 \pm 1.2$ & $26.1 \pm 1.7$ \\
\hline $0.5 \mathrm{mg} \mathrm{TP}$ & 4 & $19.4 \pm 2.1$ & $25.0 \pm 1.5$ \\
\hline $1.0 \mathrm{mg} \mathrm{TP}$ & 4 & $20.5 \pm 1.0$ & $22.6 \pm 1.4$ \\
\hline $2.0 \mathrm{mg} \mathrm{TP}$ & 4 & $14.4 \pm 3.0^{a}$ & $16.9 \pm 3.6^{a}$ \\
\hline $5.0 \mathrm{mg} \mathrm{TP}$ & 3 & $15.6 \pm 1.8^{n}$ & $15.9 \pm 2.0^{a}$ \\
\hline
\end{tabular}

Means \pm SEM are given. Designated amount of TP (testosterone propionate) in $0.1 \mathrm{ml}$ sesame oil was injected subcutaneously twice weekly for the first 4 postaxotomy weeks and once weekly thereafter for additional 6 weeks. Controls received oil vehicle injection.

${ }^{a}$ Significantly different from corresponding controls $(p<0.05$; analysis of variance).

A total of 26 rats which were single-lesioned at 6 weeks of age was used. Ten of these rats were injected with $5 \mathrm{mg}$ TP in $0.1 \mathrm{ml}$ sesame oil twice weekly for the first 4 weeks, and once weekly thereafter for an additional 6 weeks. The remaining rats were injected with oil vehicle and served as controls. Twelve weeks after axotomy, rats from both groups were reanesthetized with chloral hydrate, and the right and left hypoglossal nerves were exposed in the neck region for the following procedures.

One group of rats ( $n=6$ for TP-treated; $n=10$ for controls) was used to label hypoglossal neurons projecting via the medial branch of the nerve to innervate muscles of the tongue. This was carried out by severing the lateral branch of the hypoglossal nerve bilaterally prior to injecting $50 \mu \mathrm{l} 10 \%$ HRP solution (type VI, dissolved in saline) into the midline of the tongue. In remaining rats $(n=4$ for TP-treated; $n=6$ for controls), the trunk of the hypoglossal nerve on both sides was bathed with HRP solution by dripping 2-5 $\mu$ l HRP solution at the bifurcation of the nerve in order to label hypoglossal neurons terminating near the site of nerve transection.

Twenty-four hours after HRP application, the rats were anesthetized and perfused intracardially with $1 \%$ paraformaldehyde- $1.25 \%$ glutaraldehyde in $0.1 \mathrm{M}$ phosphate buffer, $\mathrm{pH} 7.4$, preceded by a brief rinse with saline. The lower brain stem was removed, placed in the same fixative for additional $24-48 \mathrm{hr}$, and stored in $0.1 \mathrm{M}$ phosphate buffer with $10 \%$ sucrose at $4^{\circ} \mathrm{C}$ until sectioning. Serial sections of the brain stem were made transversely at $40 \mu \mathrm{m}$ thick on a freezing microtome, and alternate sections were collected for histochemical reaction for HRP according to the method of Mesulam (1978). Sections were counterstained with $1 \%$ Neutral red.

Data analysis. The statistical significance was assessed using analysis of variance and Student's $t$-test.

\section{Results}

\section{Dose-response study}

Consistent with previous findings, the present study demonstrated that transection of the hypoglossal and facial nerves of 3 - or 6-week-old female rats resulted in a $25 \%$ cell loss in the respcctivc axotomized motor nuclei 10-12 weeks after axotomy. Administration of TP attenuated such cell loss irrespective of the age axotomy was made (Table 1 ). The effect of TP treatment was, however, dose dependent. Females in both age groups treated with $0.5 \mathrm{mg} \mathrm{TP}$ did not show any significant difference in neuronal loss relative to controls, although the treatment significantly elevated plasma testosterone from that of control females, reaching one-half of control male levels (Table 2). On the other hand, females treated with 1 or $2 \mathrm{mg}$ TP (axotomy at 
Table 2. Comparison of plasma testosterone levels between males and females receiving testosterone injection following axotomy

\begin{tabular}{lll} 
Group & $n$ & $\begin{array}{l}\text { Plasma testosterone } \\
(\mathrm{ng} / \mathrm{ml})\end{array}$ \\
\hline Male controls & 8 & $2.13 \pm 0.30$ \\
Female controls & 8 & $0.32 \pm 0.02$ \\
Female $0.5 \mathrm{mg} \mathrm{TP}$ & 7 & $1.11 \pm 0.07^{a}$ \\
Female $1.0 \mathrm{mg} \mathrm{TP}$ & 5 & $2.80 \pm 0.08^{a}$ \\
Female $2.0 \mathrm{mg} \mathrm{TP}$ & 5 & $4.11 \pm 0.71^{a}$
\end{tabular}

Means \pm SEM are given. Designated amount of TP (testosterone propionate) in $0.1 \mathrm{ml}$ sesame oil was injected subcutaneously twice weekly for the first 4 postaxotomy weeks and once thereafter for additional 6 weeks. Female controls received oil vehicle injection. Male controls received no injection after axotomy. Blood samples were collected within $16-20 \mathrm{hr}$ of the final TP or oil vehicle injection.

${ }^{a}$ Significantly different from male and female controls $(p<0.01$; analysis of variance).

3 weeks of age) or with 2 or $5 \mathrm{mg}$ TP (axotomy at 6 weeks of age) had a significant reduction in neuronal loss compared with their respective controls.

\section{Effect of TP treatment on different regions of the hypoglossal nucleus}

When differential cell counts, described elsewhere (Yu, 1988), were made in the hypoglossal nucleus of rats treated with the highest dose of TP $(2.0 \mathrm{mg}$ for rats axotomized at 3 weeks of age, and $5.0 \mathrm{mg}$ for rats axotomized at 6 weeks of age) and compared with their respective controls, TP treatment significantly reduced neuronal loss in the caudal region of the nucleus in both age groups (Table 3 ). In the rostral region of the nucleus, however, TP affected only those axotomized at 3 weeks of age but not those axotomized at 6 weeks of age. Thus, the hypoglossal nucleus appears to acquire differential sensitivity to testosterone with maturity. The finding that a sex difference in neuronal loss was present throughout the entire hypoglossal nucleus of rats axotomized at 3 weeks of age, but was restricted to the caudal region of the hypoglossal nucleus when axotomy was done at 6 weeks of age ( $\mathrm{Yu}, 1988)$, supports this view.

\section{Time-course study}

As shown in Table 4, both TP-treated and control groups had a similar degree of neuronal loss at 1 and 4 weeks postaxotomy, the range being $10-15 \%$. Thereafter, neuronal loss in the control

\section{Table 3. Effect of testosterone on cell loss in the different regions of} hypoglossal nucleus 10-12 weeks after axotomy

\begin{tabular}{llll} 
& & \multicolumn{2}{l}{$\%$ Neuronal loss } \\
\cline { 3 - 4 } Group & $n$ & Caudal region & $\begin{array}{l}\text { Rostral } \\
\text { region }\end{array}$ \\
\hline Axotomy at 3 & weeks of age & & \\
Controls & 8 & $29.3 \pm 2.2$ & $14.5 \pm 1.6$ \\
$2.0 \mathrm{mg} \mathrm{TP}$ & 5 & $17.9 \pm 3.4^{a}$ & $6.5 \pm 2.0^{a}$ \\
Axotomy at 6 weeks of age & & \\
Controls & 4 & $32.7 \pm 1.8$ & $8.7 \pm 3.1$ \\
$5.0 \mathrm{mg} \mathrm{TP}$ & 3 & $18.5 \pm 3.9^{a}$ & $9.7 \pm 3.0$ \\
\hline
\end{tabular}

$\overline{\text { Means } \pm \text { SEM are given. Designated amount of TP (testosterone propionate) in }}$ $0.1 \mathrm{ml}$ sesame oil was injected subcutaneously twice weekly for the first 4 postaxotomy weeks and once weekly thereafter for an additional 6 weeks.

${ }^{a}$ Significantly different from corresponding controls $(p<0.05 ; t$ test).
Table 4. Time-course study on the effect of testosterone treatment on neuronal loss after axotomy at 6 weeks of age

Post-

\begin{tabular}{|c|c|c|}
\hline \multirow{2}{*}{$\begin{array}{l}\text { axotomy } \\
\text { time in } \\
\text { weeks }\end{array}$} & \multicolumn{2}{|c|}{$\%$ Neuronal loss } \\
\hline & Controls $(n)$ & TP-treated $(n)$ \\
\hline
\end{tabular}

Hypoglossal nucleus

$\begin{array}{rrr}1 & 9.0 \pm 2.0(6) & 8.4 \pm 2.7(5) \\ 4 & 11.6 \pm 0.7(4) & 14.1 \pm 2.3(3) \\ 12 & 22.3 \pm 2.7(7) & 15.6 \pm 1.8(3)^{a} \\ 20 & 20.4 \pm 1.1(3) & 14.0 \pm 1.7(3)^{a}\end{array}$

Facial nucleus

$\begin{array}{rll}1 & 10.7 \pm 2.8(6) & 11.0 \pm 2.2(5) \\ 4 & 12.3 \pm 2.1(4) & 13.0 \pm 3.6(3) \\ 12 & 22.0 \pm 1.2(7) & 15.9 \pm 2.0(3)^{a} \\ 20 & 24.0 \pm 3.8(3) & 12.6 \pm 3.6(3)^{a}\end{array}$

Means \pm SEM are given. Rats in TP-treated group received subcutaneous injection of $5 \mathrm{mg}$ testosterone propionate in $0.1 \mathrm{ml}$ sesame oil twice weekly for the first 4 postaxotomy weeks and once weekly thereafter for additional 6 weeks. Controls received oil vehicle injection.

a Significantly different from corresponding controls $(p<0.05 ; t$ test).

group continued to increase with time, reaching about $25 \%$ by 12 and 20 weeks postaxotomy, whereas neuronal loss in the TP. treated group remained unchanged from the 4-week postaxotomy period onward.

\section{Immediate versus delayed start of TP treatment}

The suspension of TP treatment during the first 4 postaxotomy weeks did not affect the efficacy of hormonal treatments on neuronal survival. Neuronal loss in both motor nuclei was reduced to about $10 \% 12$ weeks after axotomy (Table 5). In contrast, immediate but brief TP treatment, a regimen effective in accelerating regeneration of the hypoglossal nerve ( $\mathrm{Yu}$ and Srinivasan, 1981; Yu, 1982b, 1984), was unable to reduce neuronal loss, which, at $25 \%$ for both motor nuclei, was not different from that of oil-vehicle-injected controls (Table 1).

\section{Axonal projections and terminations of the surviving neurons}

When hypoglossal neurons were labeled with HRP transported retrogradely by the medial branch of the hypoglossal nerve 12 weeks after axotomy, HRP-labeled neurons on the intact side were found to be localized exclusively in the ventral subnuclear group (Fig. 1). This group of neurons projects by the medial branch of the nerve to innervate muscles of the tongue (Kram-

Table 5. Comparison of neuronal loss in rats treated with testosterone at different postaxotomy times

\begin{tabular}{lcll} 
& & \multicolumn{2}{l}{ \% Neuronal loss } \\
\cline { 3 - 4 } TP treatment & $n$ & $\begin{array}{l}\text { Hypoglossal } \\
\text { nucleus }\end{array}$ & $\begin{array}{l}\text { Facial } \\
\text { nucleus }\end{array}$ \\
\hline 1st 3 weeks & 6 & $22.3 \pm 5.1$ & $24.2 \pm 2.9$ \\
5-10th weeks & 10 & $6.3 \pm 1.4^{a}$ & $12.2 \pm 2.5^{a}$ \\
\hline
\end{tabular}

Means \pm SEM are given. Axotomy was made at 6 weeks of age and neuronal numbers were counted 12 weeks after axotomy. TP (testosterone propionate), 5 $\mathrm{mg}$, in $0.1 \mathrm{ml}$ sesame oil was injected subcutaneously either twice weekly for the first 3 postaxotomy weeks or once weekly for 6 weeks beginning at the 5 th postaxotomy week.

a Significantly different from corresponding nucleus in the 5-10 week group ( $p<$ $0.01 ; t$ test). 

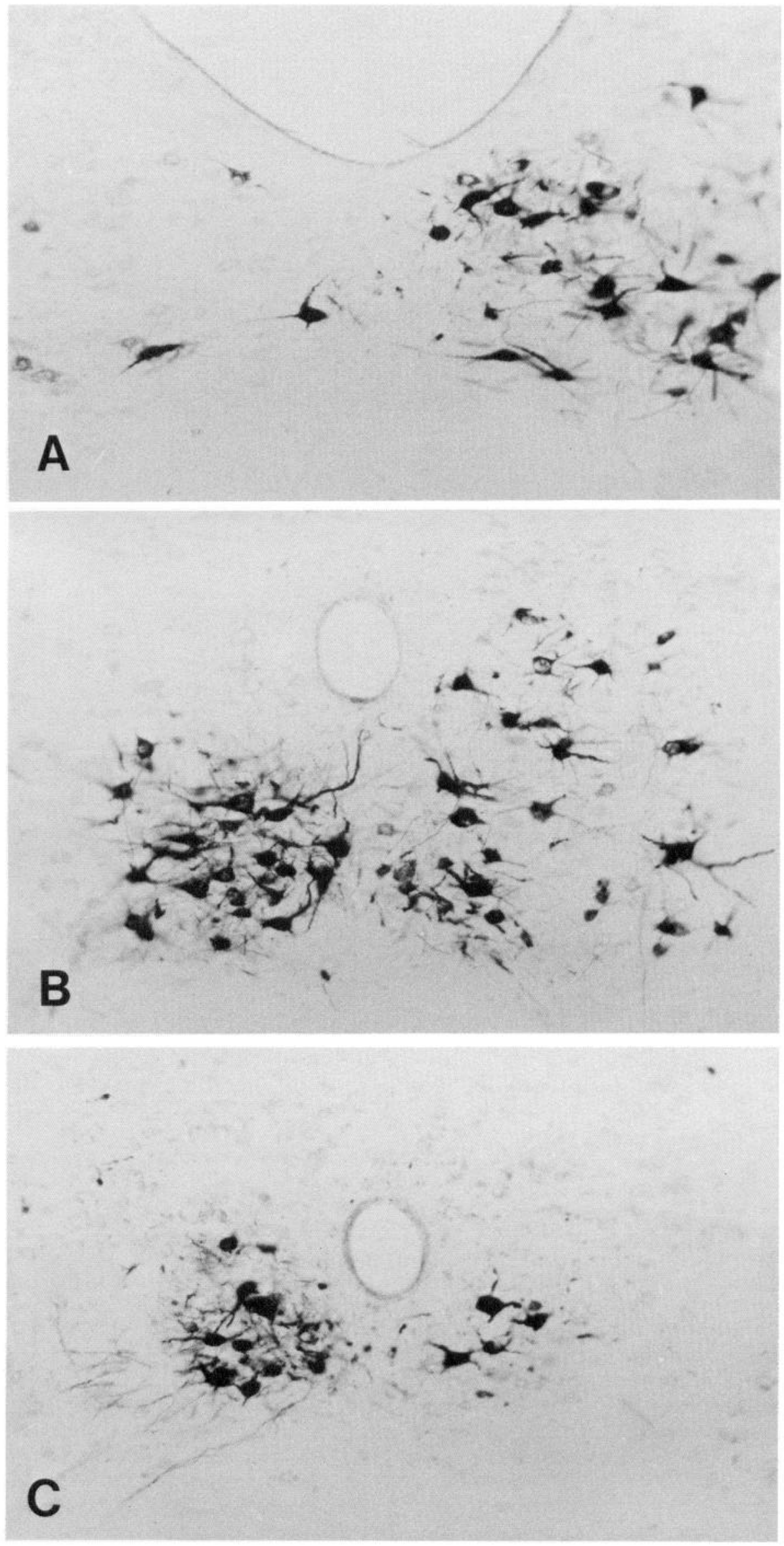

Figure 1. Distribution of HRP-labeled neurons from the rostral to caudal levels $(A-C)$ of the hypoglossal nucleus after retrograde axonal transport of HRP by the medial branch of the hypoglossal nerve. HRP was injected into the tongue 12 weeks after transection of the right hypoglossal nerve. HRP-labeled neurons in the left nucleus (intact side) were confined within the ventral subnuclear group; in the right nucleus (axotomized side), HRP-labeled neurons were scattered throughout the dorsal and ventral subnuclear groups, indicating that surviving neurons consist of those projecting normally and aberrantly into the muscles of the tongue. 
Figure 2. Distribution of HRP-labeled neurons at the rostral and caudal levels $(A$ and $B)$ of the hypoglossal nucleus after the hypoglossal nerve trunks at their bifurcation were bathed with HRP solution. The right hypoglossal nerve was transected proximal to the bifurcation 12 weeks earlier. HRP-labeled neurons were found in the right (axotomized) but not in the left (intact) nucleus, indicating that neurons which had terminated near the transection site survived also.
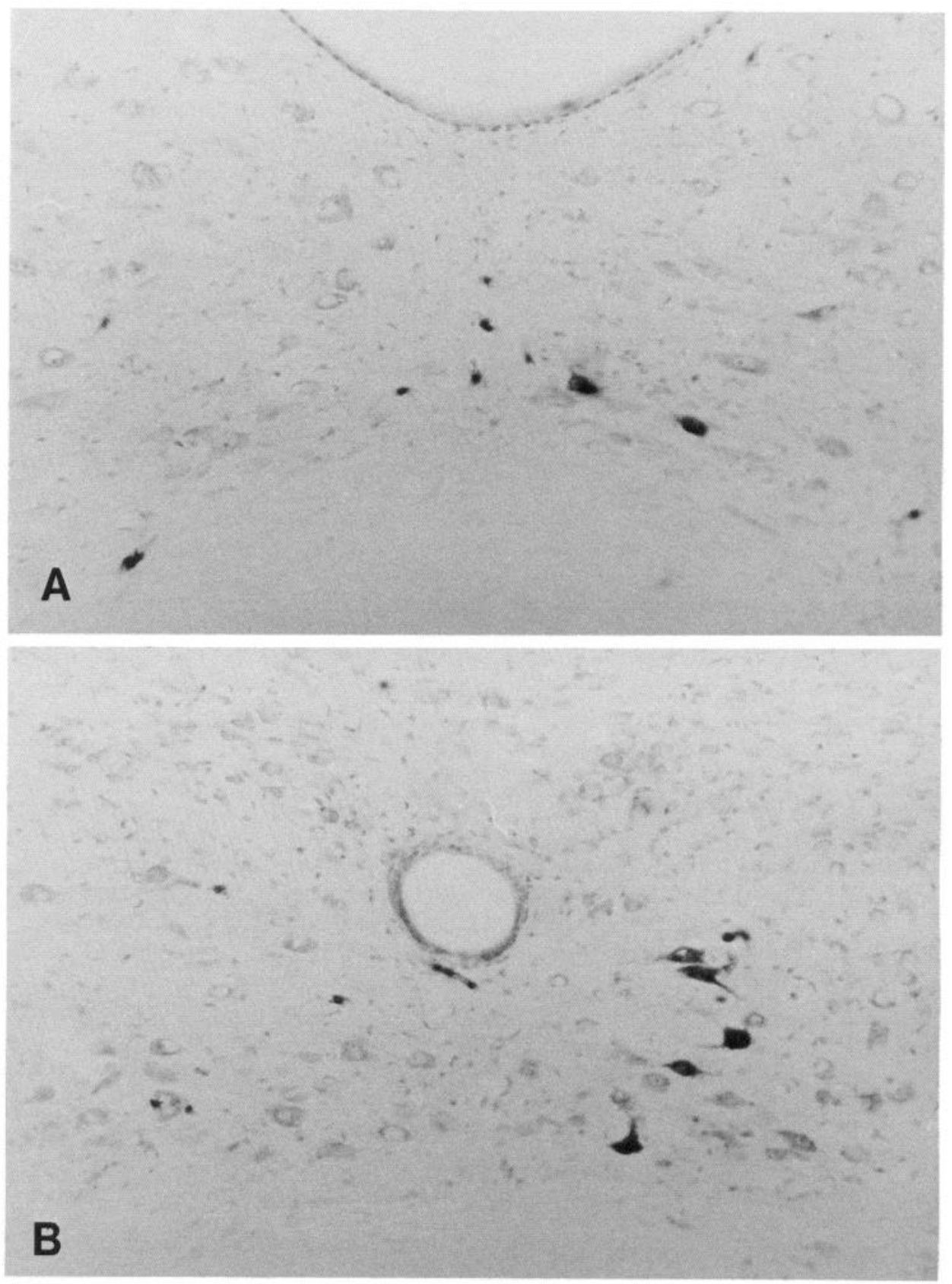

mer et al., 1979). On the axotomized side, however, labeled neurons were found to be spread out in both the ventral and dorsal subnuclear groups. Furthermore, labeled neurons on the intact side were closely packed together, whereas they were scattered on the axotomized side (Fig. $1 B$ ). These peculiar features on the axotomized side were seen in all rats examined, irrespective of the status of the treatment.

When hypoglossal nerve trunks were bathed with HRP solution in the region of the bifurcation where the right nerve had been transected 12 weeks earlier, the hypoglossal nucleus of the intact side was completely devoid of labeled neurons (Fig. 2), consistent with reports that bathing of the peripheral nerve trunk normally did not result in labeling of neuronal cell bodies (Oldfield and McLachlan, 1977; Sparrow and Kiernan, 1979). In contrast, a few HRP-labeled neurons were observed throughout the hypoglossal nucleus on the axotomized side, irrespective of the status of the treatment. Thus, those hypoglossal neurons projecting aberrantly or terminating near the transection site were among the surviving neurons, and TP treatment had no effect in altering the course of their occurrence. Since the number of HRP-labeled neurons varied greatly among individual rats, depending mainly on the amount of HRP given, comparisons of numbers of labeled neurons between TP-treated and control groups were not made.

\section{Discussion}

The results of the present study indicate that long-term treatment with testosterone significantly improved neuronal survival after axotomy in prepubertal and young adult female rats. Testosterone treatment attenuates neuronal loss in a dose- and timedependent manner in that only doses which elevated blood testosterone to levels comparable to or surpassing normal male 
levels were effective. Moreover, neuronal loss commenced about a month after axotomy was prevented by hormonal treatment, but the loss which occurred earlier was unaffected by testosterone treatment. The treatment regimen previously found to accelerate nerve regeneration ( $\mathrm{Yu}$ and Srinivasan, 1981; $\mathrm{Yu}, 1982 \mathrm{~b}$, 1984) had no effect on neuronal survival. Aberrant projections or terminations did not imperil neuronal survival, and TP treatment had no effect in altering the coursc of their occurrence.

The finding that testosterone promotes axonal outgrowth and effectuates neuronal survival is significant in that it expands the function of testosterone to the new role of having neurotrophic attributes on motoneurons in adulthood. The process of axonal outgrowth following axotomy is initiated shortly after nerve transection, with axon terminals reappearing in the denervated muscle at the end of the second week of axotomy (Yu, 1982a, b). The effect of testosterone facilitating axonal outgrowth becomes evident during this period. Both young adult male and female rats treated with the hormone respond with accelerated nerve regeneration (Yu and Srinivasan, 1981; Yu, 1982b). Nerve regeneration in prepubertal rats, however, was not affected by the hormonal treatment ( $\mathrm{Yu}, 1984)$. Testosterone treatment was ineffective in preventing neuronal loss occurring early in the first 4 weeks after axotomy but was effective in reducing neuronal loss during the 5-12th week postaxotomy period, during which most of the regenerating axons had reached their targets and functional connections had been established (Smith et al., 1984). Furthermore, an immediate but brief testosterone treatment, which is effective in accelerating nerve regeneration, is found to be insufficient to prevent neuronal loss. In contrast, the abeyance of the same treatment until the 5th week after axotomy does not diminish its efficacy on neuronal survival. These findings corroborate the data of our previous study (Yu, 1988), in which we reported that there was a sex difference in neuronal loss even in rats axotomized at 3 weeks of age, several weeks before the appearance of a gender difference in circulating testosterone levels (Döhler and Wuttke, 1975; Corpéchot et al., 1981). It is our interpretation that the presence of high (male) levels of testosterone a few weeks after axotomy, rather than at the time of axotomy, is important for improving neuronal survival. Thus, the 2 identified neurotrophic functions of testosterone, namely, accelerating axonal outgrowth and promoting neuronal survival, appear to operate at different time points, with the possibility that they may be governed by an entirely different set of mechanisms.

Since both the hypoglossal and facial motoneurons and their target muscles contain androgen receptors ( $\mathrm{Yu}$ and McGinnis, 1986), either neurons, muscle, or both are potential targets of androgenic action. Recent studies on normal cell death of androgen-responsive spinal motoneurons during development appear to point to the muscle as the primary site for androgens to exert the survival-promoting effect (Sengelaub and Arnold, 1986; Rand and Breedlove, 1987; Cover and Sengelaub, 1988). The results of the present study also favor this conclusion since the effective period of testosterone treatment for neuronal survival coincides temporarily with the reinnervation of targets.

It should be noted that some of the effects of testosterone on axotomized motoneurons resemble those of nerve growth factor (NGF) on axotomized superior ganglion cells ( $\mathrm{Nja}$ and Purves, 1978), including facilitation of the return of synaptic boutons on the axotomized neuronal soma (Yu and $\mathrm{Yu}, 1981$ ). The question arises whether target-derived substances are involved, or play any role, in mediating the effect of testosterone on neu- ronal survival. During development, target-derived factors are known to be important for neuronal survival (Bennett et al., 1980; Lancer et al., 1986; Tanaka and Landmesser, 1986). Motoneurons in adults may have a similar dependency for these factors since procedures which impede nerve regeneration or prevent contact with targets resulted in a much more severe neuronal loss than a simple nerve transection (Søreide, 1981; Snider and Thanedar, 1989). Recently, a neurotrophic factor which promotes the survival of developing motoneurons in vivo has been identified in chick hindlimbs (Oppenheim et al., 1988). The partially purified hindlimb extract is distinct from NGF and acts specifically on a subpopulation of motoneurons innervating the skeletal muscle. It will be of interest to determine whether the expression of this factor is reiterated in adults during denervation and reinnervation, and whether testosterone is involved in any way in the regulation of its expression.

We reported previously that following transection of the hypoglossal nerve, the regenerating axons grew into nerve branches at random independent of testosterone treatment ( $\mathrm{Yu}, 1982 \mathrm{~b})$. Consequently, the characteristic somatotopic organization and projection of the hypoglossal nucleus (Krammer et al., 1979) was absent in the axotomized nucleus when neural connections were traced 4 weeks after axotomy. If aberrantly projected neurons were more susceptible than normally projected neurons to neuronal loss, the former would be no longer present at the end of the period of neuronal loss, and the normal somatotopic organization of the nucleus would be restored. Data from the present study indicate no such preferential elimination of aberrantly projected neurons, since the HRP tracing study made at 12 weeks after axotomy still revealed widespread distribution of HRP-labeled neurons in both the dorsal and ventral subnuclear groups of the hypoglossal nucleus, even though HRP was transported by the medial branch of the nerve only. Moreover, those neurons terminating near the transection site also remained viable 12 weeks after axotomy. These results could be taken to indicate that neuronal loss in adults induced by axotomy could not be entirely due to the loss of contact with targets or innervation of muscles formerly not associated with. This view is supported by recent reports that hypoglossal motoneurons can survive target deprivation for prolonged periods (Snider and Thanedar, 1989) and that the neurotrophic factor of the hindlimb extract can enhance survival of motoneurons throughout the lumbar spinal cord, as well as those in the thoracic (nonlimb) region (Oppenheim et al., 1988).

In conclusion, the results reported here demonstrate that testosterone attenuates neuronal loss in a dose- and time-dependent manner. The 2 identified trophic functions of testosterone, that of accelerating axonal outgrowth and promoting neuronal survival, appear to operate under a different set of mechanisms. The time course of its effect on neuronal survival suggests the involvement of target interactions.

\section{References}

Bennett, M. R., K. Lai, and V. Nurcombe (1980) Identification of embryonic motoneurons in vitro: Their survival is dependent on skeletal muscle. Brain Res. 190: 537-542.

Breedlove, S. M., and A. P. Arnold (1980) Hormone accumulation in a sexually dimorphic motor nucleus of the rat spinal cord. Science 210: 564-566.

Commins, D., and P. Yahr (1985) Autoradiographic localization of estrogen and androgen receptors in the sexually dimorphic area and other regions of the gerbil brain. J. Comp. Neurol. 231: 473-489.

Corpéchot, C., E. E. Baulieu, and P. Robel (1981) Testosterone, dihy- 
drotestosterone and androstanediols in plasma, testes and prostates of rats during development. Acta Endocrinol. 96: 127-135.

Cover, A. R., and D. R. Sengelaub (1988) Androgen treatment does not prevent the death of sexually dimorphic rat spinal motoneurons following early target removal. Soc. Neurosci. Abstr. 14: 706.

Döhler, K. D., and W. Wuttke (1975) Changes with age in levels of serum gonadotropins, prolactin, and gonadal steroids in prepubertal male and female rats. Endocrinology 97: 898-907.

Krammer, E. B., T. Rath, and M. F. Lischka (1979) Somatotopic organization of the hypoglossal nucleus: A HRP study in the rat. Brain Res. 170: 533-537.

Krieg, M. (1976) Characterization of the androgen receptor in the skeletal muscle of the rat. Steroids $28: 261-274$.

Kurz, E. M., D. R. Sengelaub, and A. P. Arnold (1986) Androgens regulate the dendritic length of mammalian motoneurons in adulthood. Science 232: 395-398.

Lancer, M. E., J. L. Carrington, and J. F. Fallon (1986) Survival of motoneurons in the brachial lateral motor column of limbless mutant chick embryos depends on the periphery. J. Neurosci. 6: 2551-2557.

Lieberburg, I., L.C. Krey, and B. S. McEwen (1979) Sex differences in serum testosterone and in exchangeable brain cell nuclear estradiol during the neonatal period in rats. Brain Res. 178: 207-212.

McGinnis, M. Y., P. J. Davis, M. J. Meaney, M. Singer, and B. S. McEwen (1983) In vitro measurement of cytosol and cell nuclear androgen receptors in male rat brain and pituitary. Brain Res. 275: 75-82.

Mesulam, M. M. (1978) Tetramethyl benzidine for horseradish peroxidase neurochemistry: A noncarcinogenic blue reaction-product with superior sensitivity for visualizing neural afferents and efferents. $J$. Histochem. Cytochem. 26: 106-117.

$\mathrm{Nja}, \mathrm{A}$., and D. Purves (1978) The effects of nerve growth factor and its antiserum on synapses in the superior cervical ganglion of the guinea-pig. J. Physiol. (Lond.) 277: 53-75.

Nordeen, E. J., K. W. Nordeen, D. R. Sengelaub, and A. P. Arnold (1985) Androgens prevent normally occurring cell death in a sexually dimorphic spinal nucleus. Science 229: 671-673.

Oldfield, B. J., and E. M. McLachlan (1977) Uptake and retrograde transport of HRP by axons of intact and damaged peripheral nerve trunks. Neurosci. Lett. 6: 135-141.

Oppenheim, R. W., L. J. Haverkamp, D. Prevette, J. L. McManaman, and S. H. Appel (1988) Reduction of naturally occurring motoneuron death in vivo by a target-derived neurotrophic factor. Science 240 : 919-922.

Rand, M. N., and S. M. Breedlove (1987) Ontogeny of functional innervation of bulbocavernosus muscles in male and female rats. Dev. Brain Res. 33: 150-152.

Sar, M., and W. E. Stumpf (1977) Androgen concentration in motor neurons of cranial nerves and spinal cord. Science 197: 77-79.
Sengelaub, D. R, and A. P. Arnold (1986) Development and loss of early projections in a sexually dimorphic rat spinal nucleus. J. Neurosci. 6: 1613-1620.

Sheridan, P. I., and F. J. Weaker (1981) The primate spinal cord is a target for gonadal steroids. J. Neuropathol. Exp. Neurol. 40: 447453.

Sheridan, P. J., and F. J. Weaker (1982) Androgen receptor systems in the brain stem of the primate. Brain Res. 235: 225-232.

Smith, C. B., A. M. Crane, M. Kadekaro, B. W. Agranoff, and L. Sokoloff (1984) Stimulation of protein synthesis and glucose utilization in the hypoglossal nucleus induced by axotomy. J. Neurosci. 4: 2489-2496.

Snider, W. D., and S. Thanedar (1989) Target dependence of hypoglossal motor neurons during development and in maturity. J. Comp. Neurol. 279: 489-498.

Snochowski, M., E. Dahlberg, and J. A. Gustafsson (1980) Characterization and quantification of the androgen and glucocorticoid receptors in cytosol from rat skeletal muscle. Eur. J. Biochem. 111: 603-616.

Sparrow, J. R,. and J. A. Kiernan (1979) Uptake and retrograde transport of proteins by regenerating axons. Acta Neuropathol. (Berl.). 47: $39-47$.

Søreide, A. J. (1981) Variations in the axon reaction after different types of nerve lesion. Light and electron microscopic studies on the facial nucleus of the rat. Acta Anat. 110: 173-188.

Tanaka, H., and L. T. Landmesser (1986) Cell death of lumbosacral motoneurons in chick, quail, and chick-quail chimera embryos: A test of the quantitative matching hypothesis of neuronal cell death. J. Neurosci. 6: 2889-2899.

Yu, W. H. A. (1982a) Sex differences in the regeneration of the hypoglossal nerve in rats. Brain Res. 238: 404-406.

$\mathrm{Yu}, \mathrm{W} . \mathrm{H}$. A. (1982b) Effects of testosterone on the regeneration of the hypoglossal nerve in rats. Exp. Neurol. 77: 129-141.

$\mathrm{Yu}, \mathrm{W}$. H. A. (1984) Responsiveness of hypoglossal neurons to testosterone in prepubertal rats. Brain Res. Bull. 13: 667-672.

$\mathrm{Yu}$, W. H. A. (1988) Sex difference in neuronal loss induced by axotomy in the rat brain stem motor nuclei. Exp. Neurol. 102: 230235.

Yu, W. H. A., and M. Y. McGinnis (1986) Androgen receptor levels in cranial nerve nuclei and tongue muscles in rats. J. Neurosci. 6: 1302-1307.

Yu, W. H. A., and R. Srinivasan (1981) Effect of testosterone and $5 \alpha-$ dihydrotestosterone on regeneration of the hypoglossal nerve in rats. Exp. Neurol. 71: 431-435.

Yu, W. H. A., and M. C. Yu (1981) Accelerated restoration of central synapses on chromatolytic neurons by testosterone. Anat. Rec. 199: 286A. 